\title{
Influence of the Processing Parameters on the Dispersion and Coloration Behavior of a Halogenated Copper Phthalocyanine-Based Masterbatch
}

\author{
MAURO BUCCELLA, ANDREA DORIGATO \\ Department of Industrial Engineering and INSTM Research Unit,University of Trento, Via Sommarive 9, 38123 Trento, Italy
}

\author{
FABIO RIZZOLA, MAURO CALDARA \\ Aquafil Spa, Via Linfano 9, 38062 Arco (Trento), Italy
}

\section{LUCA FAMBRI}

Department of Industrial Engineering and INSTM Research Unit,University of Trento, Via Sommarive 9, 38123 Trento, Italy

Correspondence to: A. Dorigato; e-mail: andrea.dorigato@ing.unitn.it

Received: February 22, 2016

Accepted: May 11, 2016

\begin{abstract}
A monodispersed green masterbatch was produced through an industrial extrusion process, by mixing a commercial Polyamide 6 matrix (PA6) with a halogenated copper phthalocyanine green pigment. The production process was investigated and optimized in order to improve the pigment dispersion, reducing the clogging power and increasing the color strength of the resulting products. The compounding process based on three extrusions without filtration led to a filter pressure value (FPV) reduction of about $84 \%$ and a relative color strength (RCS) increase of about $50 \%$ with respect to the standard production process (i.e single extrusion). The thermal stability of the prepared compounds was evaluated by rheological test, viscosity measurements, and end group analysis, and it was found that a triple extrusion without filtration promoted thermo-oxidative matrix degradation. However, the same processing conditions led to a significant reduction of the production waste, increasing the productivity and the quality of the final product. (c) 2016 Wiley Periodicals, Inc. Adv Polym Technol 2018, 37, 21721; View this article online at wileyonlinelibrary.com. DOI 10.1002/adv.21721
\end{abstract}

KEY WORDS: Coloration behavior, Dispersion, Processing parameters

\section{Introduction}

$\mathrm{t}$ is widely recognized that coloration technology has always played a strategic role in our society, especially from an anthropological, esthetic, functional, and economical point of view. ${ }^{1,2}$ Also, plastic materials market is strictly connected to the coloration industry, because of the growing need of multifunctional color masterbatches possessing elevated physical and chemical properties.

Generally speaking, the industrial coloration of plastic materials can be performed in two ways: using soluble dyes or color pigments. ${ }^{3}$ Soluble dyes are constituted by organic substances that can be solubilized with the plastic substrate. Thanks to their good chemical affinity with the polymer matrix, the homogeneity and the optical transparency of the compounded materials can be retained. Color pigments are very fine and insoluble particles that maintain their original properties both during the manufacturing processes and during the service life of the plastic product. ${ }^{3}$ The coloration of the plastic medium can be achieved through a selective light absorption in the visible spectrum. ${ }^{1}$ Color pigments have to satisfy some requirements: (i) total insolubility in the incorporating matrix, (ii) easy dispersability within the polymer, (iii) chemical stability under severe thermo-mechanical processing conditions, (iv) compatibility with the other additives used, (v) non-toxicity, and (vi) environmental compatibility., ${ }^{4,5}$ Except for titanium dioxide $\left(\mathrm{TiO}_{2}\right)$, inorganic pigments possess elevated light absorption capability and low scattering. Compared to organic pigments, they are characterized by an elevated stability at high temperatures (up to $300^{\circ} \mathrm{C}$ ), but they possess a lower color strength. ${ }^{6}$ Considering that their high surface energy promotes the wettability of the primary particles and reduces agglomeration phenomena, inorganic pigments can be easily dispersed in polymers even at low shear stresses. ${ }^{5}$ In the plastic industry, the most commonly used 
inorganic pigments are CI Pigment White $6\left(\mathrm{TiO}_{2}\right)$ and CI Pigment Black 7 (Carbon Black). Organic pigments are constituted by polycyclic molecules containing chromophoric groups. Because of their relative insolubility in most polymeric matrixes, they possess a lower dispersability with respect to organic pigments, especially in polyolefins. Their heat resistance is often limited to $280^{\circ} \mathrm{C} .^{5}$ Unlike inorganic pigments, organic pigments were shown to play a marked nucleating effect on polymer matrixes, increasing crystallization kinetics. The most industrially utilized organic pigments are blue and green copper phthalocyanine (CI Pigment Blue 15:3 and CI Pigment Green 7) and violet dioxazine (CI pigment violet 23). ${ }^{5}$

In the coloration industry, pigments are not directly used in powder form, but they must be previously compounded with polymers for the production of monoconcentrated masterbatches, in a filler concentration interval from 5 to $40 \mathrm{wt} \%$. These concentrates are added to the polymers through an extrusion process in the so-called mass coloration process. ${ }^{4,5}$ The preliminary preparation of monodispersed masterbatches is generally preferable in terms of safety (i.e., avoiding of dust in the working place) and in terms of product quality (i.e., better pigments dispersion, higher color strength, reduced cleaning time). ${ }^{3}$

Mass coloration process can be generally performed in two steps: (i) preparation of the monodispersed masterbatch and (ii) its additivation to the polymer matrix. ${ }^{5}$ Monoconcentrated masterbatches can be prepared by mixing together the pigment powder and the polymer matrix in an extrusion process. During this process, the breakage of the primary particle aggregates occurs, thus improving the polymer-particles interfacial wettability. This process can be improved by utilizing elevated processing temperatures and a low-viscosity matrix. ${ }^{8,9}$ The dispersion quality of the pigments in the host polymer and their aggregation tendency depend on the physical properties of pigment particles (i.e., size, shape, surface properties, crystalline structure, chemical composition of the primary crystals). ${ }^{4}$ On the contrary, pigment aggregation during the production process leads to heavy technical limitations like reduction of the mechanical properties, filament breakage during spinning, bad coloration quality, and economical disadvantages due to the increase in the production times and scraps. ${ }^{4}$ Amorphous particles have higher surface energy compared to crystalline particles. Moreover, smaller primary particles are characterized by a higher surface energy and thus have a marked tendency to agglomerate or to absorb other chemical species (i.e., solvents or surfactants). ${ }^{1}$ In the papers of Deshmukh et $\mathrm{al}^{3}$ and Ahmed et $\mathrm{al}^{4}$ it was shown that the most critical pigments to disperse in a polymer matrix are CI Pigment Blue 15:3, CI Pigment Green 7, and CI Pigment Violet 23.

The investigation of the pigment dispersion within the matrix is a key point for the color masterbatch quality. Direct experimental techniques are microstructural analysis and $\mathrm{X}$ ray fluorescence (EDX), while indirect methods (i.e., FilterTest, color strength, and rheological measurements ${ }^{4}$ ) are more representative because they are correlated with the production process and with the optical properties of yarns. ${ }^{5}$ To the best of our knowledge, only few articles focused on the analysis of the production process of monodispersed masterbatch and on the optimization of pigment dispersion in polymer matrixes can be found in open literature. For instance, Suresh et al studied pigment dispersion in a low-density polyethylene matrix comparing different kinds of monodispersed masterbatches. ${ }^{3}$ Joshi et al investigated the effect of surfactant agent on the particle dispersion by measuring torque variation in the extruder during the compounding process. ${ }^{8}$ Wo et al investigated the effect of phthalocyanine pigments on the crystallization behavior of polypropylene. ${ }^{7}$ Ahmed et al compared the mechanical properties of polypropylene fibers obtained using pigments in powder form and monodispersed masterbatches. ${ }^{4}$ Moreover, a detailed description of pigments and their effects on the fibers produced through a spinning process was performed by Marcincin. ${ }^{5}$

On the basis of these considerations, in this work, the influence of different production processes on the pigment dispersion in PA6 monoconcentrated masterbatches filled with blue phthalocyanine particles was investigated. The final aim of the present experimental work was to optimize the industrial process of color masterbatch production, improving the color strength of the master, and limiting the clogging effect and the pigment consumption during spinning operations. A detailed analysis of the filterability, rheology, viscosity, and of the chemical terminations of monoconcentrated masterbatches was performed. This work represents the preliminary step of a wider investigation, focused on the properties of complex color masterbatches, obtained by mixing different monodispersed compounds.

\section{EXPERIMENTAL PART}

\section{Materials}

An Aquamid ${ }^{\circledR}$ AQ24000 PA6 resin with a relative viscosity of 2.4 was kindly supplied in form of polymeric chips by Aquafil S.p.A (Arco, Italy). A halogenated copper phthalocyanine green color pigment powder (CI PG7) was supplied by BASF (Ludwigshafen, DE). The most important physical properties of the PA6 matrix and of the color pigment are summarized in Table I. The chemical structure of halogenated copper phthalocyanine green color pigment is represented in Fig. 1, while a representative SEM micrograph of these pigments is reported in Fig. 2. It is evident the aggregated morphology of this filler, with the presence of agglomerated primary particles with irregular shape, having a mean size of $70 \mathrm{~nm}$. Through BET analysis and helium picnometry, the surface properties, the density of the pigments, and the theoretical dimension of primary particles were determined. Moreover, through light scattering measurements it was possible to estimate the mean diameter of the agglomerates and the number of primary particles. The most important results are summarized in Table II.

\section{Monoconcentrated Masterbatches Preparation}

Green monodispersed masterbatches were prepared through a traditional melt compounding and extrusion process. Powdered Aquamid 24000 and halogenated copper phthalocyanine pigments were mixed using a turbo mixer at a constant filler concentration of $25 \mathrm{wt} \%$. The mixture was then extruded in a co-rotating twin screw extruder, having a screw diameter of $58 \mathrm{~mm}$ and a $L / D$ ratio of 44 . The following 
TABLE I

Physical properties of PA6 and of copper phthalocyanine blue pigment (PB15:3)

\begin{tabular}{lll}
\hline Property & AQ 24000 & \multicolumn{1}{c}{ PG7 } \\
\hline Molecule & Polyamide 6 & $\begin{array}{l}\text { Halogenated Copper } \\
\text { phthalocyanine } \beta\end{array}$ \\
CAS number & $25038-54-4$ & $1328-53-6$ \\
Chemical formula & {$\left[\mathrm{C}_{6} \mathrm{H}_{11} \mathrm{NO}\right]_{\mathrm{n}}$} & $\mathrm{C}_{32} \mathrm{H}_{3} \mathrm{~N}_{8} \mathrm{Cl}_{15} \mathrm{Cu}$ \\
Density $\left(\mathrm{g} \mathrm{cm}^{-3}\right)$ & 1.14 & 2.1 \\
$\mathrm{MW}$ & - & 1094.77 \\
$\eta_{\text {rel }}{ }^{\mathrm{a}}$ & 2.4 & - \\
$T_{m}\left({ }^{\circ} \mathrm{C}\right)$ & 222 & - \\
Particles dimension $(\mathrm{nm})$ & - & 201 \\
\hline
\end{tabular}

${ }^{a}$ Measured through an Ubbelohde viscometer at $25^{\circ} \mathrm{C}$ on sulfuric acid solutions (concentration $=10 \mathrm{~g} \mathrm{~L}^{-1}$ ).

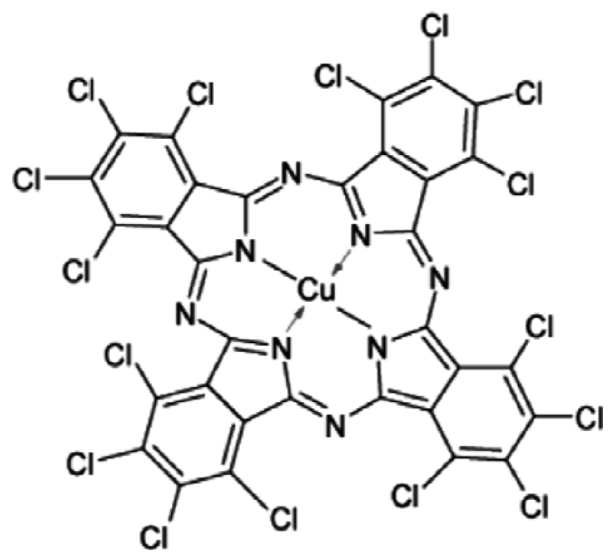

FIGURE 1. Chemical structure of copper green phthalocyanine (PG7).

processing parameters were utilized: rotational speed $=350 \mathrm{rpm}$, feed rate $=210 \mathrm{~kg} \mathrm{~h}^{-1}$, barrel temperature profile $=80 / 230 / 245 / 245 / 245 / 245 / 245 / 245 / 250 / 260^{\circ} \mathrm{C}$. Considering that the melting temperature of neat PA6 is generally reported between 220 and $230^{\circ} \mathrm{C}$, the extrusion parameters were determined after an industrial optimization process. Lower processing temperatures would limit the flowability of the material, thus increasing the clogging phaenomena, while extrusion at higher temperatures could promote the degradation of the extruded filaments.

After being extruded, the compounded materials passed through an industrial filter with a size of $60 \mu \mathrm{m}$, in order to remove the impurities and bigger agglomerates that could clog the filters and increase the probability of filament rupture during the fiber spinning process. In order to optimize the dispersion quality of the final products, four process set-ups, different for the extrusion number and for the presence of the final filtration, were considered. Physically speaking, an increase in the extrusion times could lead to a better pigment dispersion, because of the higher dispersion energy applied to the system. The different production processes were evaluated in terms of specific mechanical energy (SME), evaluated as reported in Eq. (1):

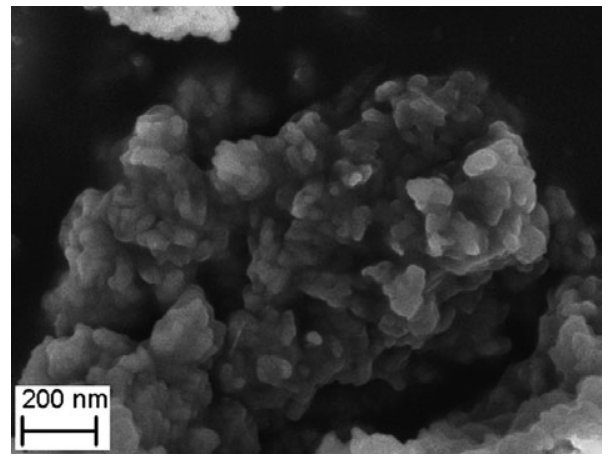

FIGURE 2. SEM micrograph of copper phthalocyanine green pigments (PG7).

$$
\mathrm{SME}=\frac{n \cdot P \cdot O}{n_{m} \cdot Q}\left[\mathrm{kWh} \mathrm{kg}^{-1}\right]
$$

Where $n$ is the screw speed, $n_{m}$ is the maximum screw rotations, $P$ is the electric power, $O$ is the engine loading, and $Q$ is the extruder capacity. SME represents the energy transfer from drive motor to the frictional heating for melting, mixing, and die pressurization in the compounding process. ${ }^{10}$ It gives an estimation of the energy consumption during the extrusion and provides some information about extruder efficiency. ${ }^{11-16}$ However, prolonged thermal treatment (i.e., elevated SME values) could promote a serious degradation of the polymer matrix. The most important parameters of the different processing conditions, with the relative specific mechanical energy (SME) values are summarized in Table III. As reported in Table III, four different experimental set-ups were considered: samples extruded one time with filtration (1 Extrusion W-F) and nonfiltered samples extruded one, two, and three times (respectively denoted as 1 Extrusion W/O-F, 2 Extrusions $\mathrm{W} / \mathrm{O}-\mathrm{F}$, and 3 Extrusions $\mathrm{W} / \mathrm{O}-\mathrm{F})$. Considering the industrial layout of this product, a further extrusion process would not be sustainable both from a technological and economical point of view. Finally, the compounded materials were pelletized and injection molded through a Battenfield Plus 350/075 machine, in order to prepare square sheets 2$\mathrm{mm}$ thick suitable for color strength measurements.

\section{EXPERIMENTAL METHODOLOGIES}

\section{Filter Pressure Value Analysis}

The dispersion of pigments inside the polymer matrix, directly correlated with the industrial filterability of monoconcentrated masterbatches, was evaluated through Filter-Test measurement, performed according to EN 13900-5 standard. ${ }^{17,18}$ Monoconcentrated masterbatches were processed through an extruder $(L=33.6 \mathrm{~cm}, L / D=24$, rotational speed $=$ $20 \mathrm{rpm}$, barrel temperature profile $=270 / 270 / 270 / 275^{\circ} \mathrm{C}$ ), and the melt was forced to pass through a filter with a size of $25 \mu \mathrm{m}$. The pressure increase due to the filter clogging was determined. ${ }^{3,5}$ Filter-Tests provided the so-called FPV (Filter Pressure Value) and FPV II (Plateau Filter Pressure Value), defined as reported in Eqs. (2) and (3): 
TABLE II

Experimental results of BET, light scattering, and density measurements on phthalocyanine pigments.

\begin{tabular}{|c|c|c|c|c|c|}
\hline Pigment & $\begin{array}{l}\text { Density } \\
{\left[\mathrm{g} \mathrm{cm}^{-3}\right]}\end{array}$ & $\begin{array}{c}\mathrm{SSA}^{\mathrm{b}} \\
{\left[\mathrm{m}^{2} \mathrm{~g}^{-1}\right]}\end{array}$ & $\begin{array}{l}d_{\mathrm{BET}} \\
{[\mathrm{nm}]}\end{array}$ & $\begin{array}{l}d_{\text {Light scattering }} \\
\quad[\mathrm{nm}]\end{array}$ & $\begin{array}{c}N \text { primary } \\
\text { particles }\end{array}$ \\
\hline Green PG7 & 2.02 & 42.9 & 69 & 243 & 4 \\
\hline
\end{tabular}

${ }^{\text {a }}$ Measured through a Micromeritics ${ }^{\circledR}$ Accupyc 1330 helyum pycnometer.

${ }^{\mathrm{b}}$ Measured through an ASAP ${ }^{\circledR} 2010$ Accelerated Surface Area and Porosimetry machine.

${ }^{\mathrm{C}}$ Measured through a Beckman Coulter-Desla ${ }^{\circledR}$ Nano C-Particle analyzer.

$$
\begin{gathered}
\mathrm{FPV}=\frac{P_{2}-P_{1}}{M} \\
\mathrm{FPV} \mathrm{II}=\frac{P_{3}-P_{1}}{M}
\end{gathered}
$$

where $P_{1}$ is the initial pressure, $P_{2}$ is the maximum pressure, $P_{3}$ is the second pressure plateau after pressure peak, and $M$ is the mass of pigment passed through the filter. A low FPV value indicates that the extrusion process led to a homogeneous dispersion of the pigments in the matrix, while an elevated FPV is correlated with a bad filler dispersion within PA6. From FPV evaluation it is possible to have an idea of the masterbatch processability and of its suitability for the spinning process, while FPVII provides information about filter clogging phenomenon. In particular, a slight pressure drop after the pressure peak is related to a physical clogging of the filter, because of the packing effect of the aggregates, while a marked pressure decrease can be determined by the presence of unstable agglomerates or gels that were broken down and pushed through filter from the molten polymer flow.

\section{Color Strength}

The color strength measures the pigment capability to impart color to a substrate under specific processing conditions. ${ }^{19,20}$ The reflectance curves of samples were determined through a Hunterlab ${ }^{\circledR}$ Colorquest XE Spectrophotometer. The measured reflectance of an optically infinite thick layer $R_{\infty}(\lambda)$ is related to the ratio of the absorption coefficient $K(\lambda)$ and the scattering coefficient $S(\lambda)$ for diffuse light according to the two-flux radiation theory of Kubelka-Munk (KM), ${ }^{21}$ as reported in Eq. (4):

$$
\frac{K(\lambda)}{S(\lambda)}=\frac{\left[1-R_{\infty}(\lambda)\right]^{2}}{2 \cdot R_{\infty}(\lambda)}
$$

From Eq. (4) the absorption coefficient $K(\lambda)$ over the whole interval of visible light was determined and weighted with the tristimulus curves, calculating thus the pigment amount necessary to obtain the same reference color intensity. The relative color strength (RCS) was determined comparing the $(K / S)$ ratio of the sample and that of a standard reference, ${ }^{17}$ as reported in Eq. (5).
TABLE III Production process set-up

\begin{tabular}{lccc}
\hline Production Process & $\begin{array}{c}\text { Number of } \\
\text { Extrusions }\end{array}$ & $\begin{array}{c}\text { Presence of } \\
\text { Filtration Process }\end{array}$ & $\begin{array}{c}\mathrm{SME} \\
{\left[\mathrm{kWh} \cdot \mathrm{kg}^{-1}\right]}\end{array}$ \\
\hline 1 Extrusion W-F & 1 & Yes & 0.25 \\
1 Extrusion W/O-F & 1 & No & 0.23 \\
2 Extrusions W/O-F & 2 & No & 0.46 \\
3 Extrusions W/O-F & 3 & No & 0.69 \\
\hline
\end{tabular}

$$
\operatorname{RCS}=\frac{(K / S)_{\text {sample }}}{(K / S)_{\text {reference }}} \cdot 100
$$

RCS determination gives an indirect indication of the pigment dispersion inside the matrix: the higher the RCS values, the better dispersion is achieved. ${ }^{22}$

\section{Rheological Characterization}

Dynamic rheological measurements were carried out through a Dynisco Polymer LCR 52M capillary rheometer, setting a chamber temperature of $260^{\circ} \mathrm{C}$ and a shear rate $(\dot{\gamma})$ interval between 100 and $10000 \mathrm{~s}^{-1}$. Before testing, pelletized samples were dried in a vacuum oven at $120^{\circ} \mathrm{C}$ for $24 \mathrm{~h}$, in order to reach a moisture content less than $0.1 \%{ }^{23}$ The samples were maintained in the rheometer for two different residence times ( 3 and $23 \mathrm{~min}$ ), in order to evaluate if the pigment promotes the thermo-oxidative degradation of the matrix or if the filler tends to agglomerate for prolonged processing times. These intervals were chosen according to the requirements of the industrial processing of polyamides. In particular, a time of $3 \mathrm{~min}$ is required to completely melt PA6 in the rheometer oven at $260^{\circ} \mathrm{C}$, while an interval of $23 \mathrm{~min}$ is the typical residence time at elevated temperature for a melt spinning process.

The Apparent viscosity is defined as the ratio between the shear stress $(\tau)$ and the shear rate $(\dot{\gamma})$ applied to a molten polymer at a specific temperature, as defined in the Eq. (6).

$$
\eta_{\text {app }}=\frac{\tau}{\dot{\gamma}}
$$

Into capillary rheometer, the molten polymer is forced to pass through a capillary at different speeds. Shear stresses are related to pressure variation before and after passing through capillary, while shear rates are related to the throughput of material, as reported in Eqs. (7) and (8).

$$
\tau=\frac{R}{2}\left(\frac{\Delta P}{L}\right)
$$

$$
\dot{\gamma}=\frac{4 Q}{\pi R^{3}}
$$

Where $R$ and $L$ are respectively the radius and the length of capillary, $\Delta P$ is the pressure variation, and $Q$ is the material flow rate. 



FIGURE 3. (a) Representative Filter-Test curves and (b) FPV and FPVII values of monoconcentrated masterbatches with different processing conditions. (Full line) 1 Extrusion W-F; (dotted line) 1 Extrusion W/O-F; (dash-dot line) 2 Extrusions W/O-F; (dashed line) 3 Extrusions W/O-F.

Apparent viscosity curves $\left(\eta_{\text {app }}\right)$ were fitted through the Cross equation $^{24,25}$ (Eq. (9)), in order to determine the values of the zero shear rate viscosity $\left(\eta_{0}\right)$ and of the $C$ parameter, that is proportional to the cohesive energy of the particles under shear stresses ${ }^{5}$

$$
\eta_{\text {app }}=\eta_{\infty}+\frac{\eta_{0}-\eta_{\infty}}{1+(C \dot{\gamma})^{m}}
$$

Where $\eta_{\infty}$ is the viscosity at the second Newtonian plateau at elevated shear rates, while $m$ coefficient is related to the slope of the pseudo-plastic interval of the rheological curve.

Relative viscosity tests were performed using an Ubbelohde viscometer according to ISO 307 standard on monoconcentrated masterbatches chips. About $0.4 \mathrm{~g}$ of samples were previously dried for $30-60 \mathrm{~min}$ in an oven at $90^{\circ} \mathrm{C}$ and solubilized at $50^{\circ} \mathrm{C}$ with sulfuric acid (purity $95.7 \%$ ), at a

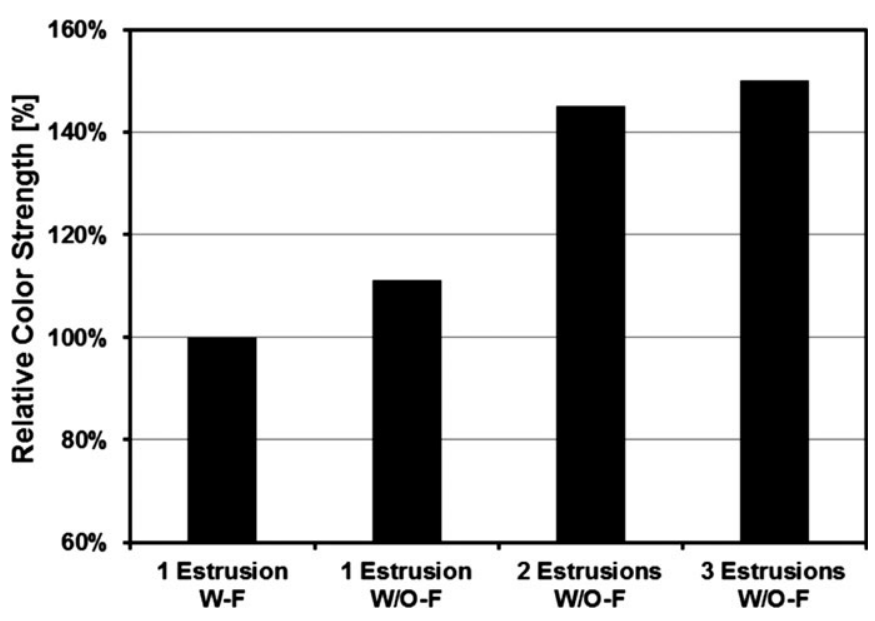

FIGURE 4. Relative color strength (RCS) of monoconcentrated green masterbatches prepared with different processing parameters.

concentration of 5 and $10 \mathrm{~g} \mathrm{~L}^{-1}$. The solution was then put in a water bath at $25^{\circ} \mathrm{C}$ for $20 \mathrm{~min}$ and then tested at the same temperature. In this way, Intrinsic Viscosity $\left(\eta_{i}\right)$ values of the samples were extrapolated. ${ }^{26}$ Relative viscosity is defined as a ratio between the flow time of a polymer solution $(t)$ and the flow time of the pure solvent $\left(t_{0}\right)$ through a capillary, as reported in the Eq. (10).

$$
\eta_{\text {rel }}=\frac{t}{t_{0}}
$$

By measuring the relative viscosity at different concentrations, the reduced viscosity $\left(\eta_{\text {red }}\right)$ and the inherent viscosity $\left(\eta_{\text {inh }}\right)$ were calculated using the Eqs. (11) and (12).

$$
\eta_{\text {red }}=\frac{\eta_{\text {rel }}-1}{c}
$$

$$
\eta_{\text {inh }}=\frac{\ln \eta_{\text {rel }}}{c}
$$

where $c$ is the solution concentration. The plots of reduced viscosity and inherent viscosity converge at zero concentration to the intrinsic viscosity $\left(\eta_{\mathrm{i}}\right)$ of the polymer, as defined in the Eq. (13).

$$
\eta_{i}=\lim _{c \rightarrow 0} \frac{\eta_{\text {rel }}-1}{c}
$$

\section{Chemical Characterization}

In order to investigate the effect of the different processing conditions on the chemical properties of the monodispersed masterbatches, end group analysis was carried on extruded pellets. A Mettler DL50 automatic titrator coupled with an 


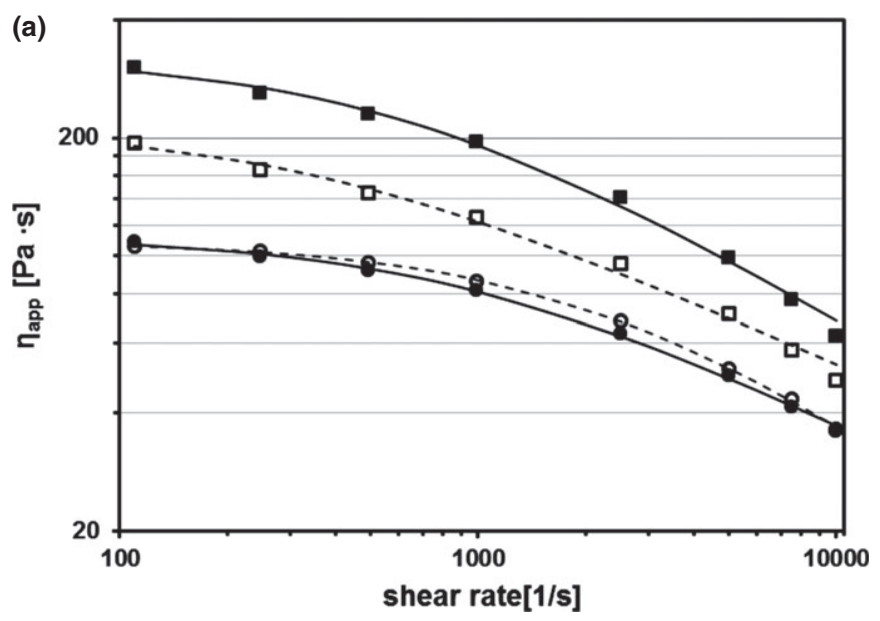

(b)

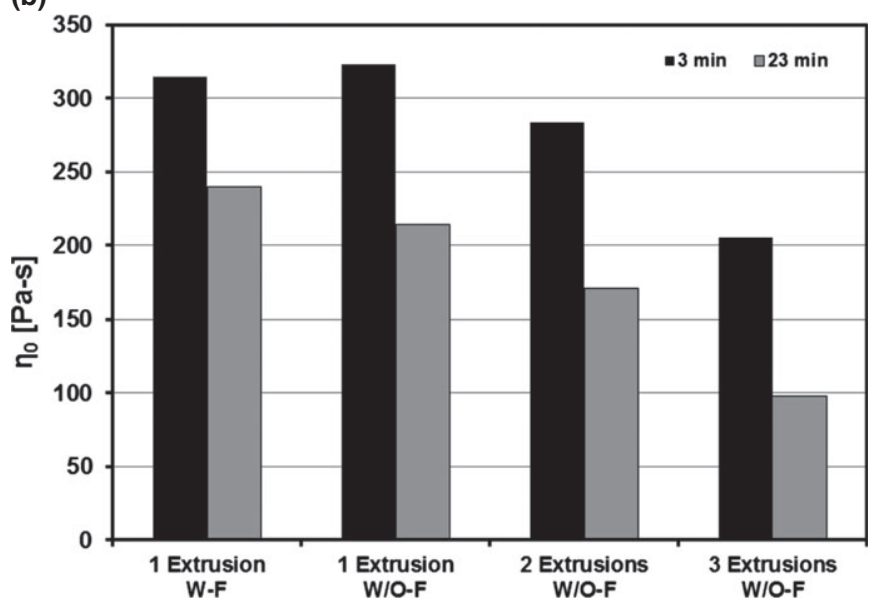

FIGURE 5. (a) Rheological curves of neat PA6 matrix with a residence time of $(\bullet)$ min and of $(\bullet) 23 \mathrm{~min}$, and rheological curves of 1 Extrusion W/O-F monodispersed green masterbatch with a residence time of (口) 3 min and (ם) 23 min. Fitting of rheological data of the compounded materials with a residence time of $3 \mathrm{~min}$ (full line) and of 23 min (dashed line) using Cross model (Eq. 6). (b) Zero shear rate viscosity values from the fitting lines through Cross model.

electronic voltmeter was used for these tests. About $0.8 \mathrm{~g}$ of samples were solubilized in $20 \mathrm{~mL}$ of 2,2,2 trifluoroethanol (TFE) at $55^{\circ} \mathrm{C}$. $-\mathrm{NH}_{2}$ group titration was performed at $25^{\circ} \mathrm{C}$ through a $\mathrm{HCl} 0.02 \mathrm{~N}$ solution, while $-\mathrm{COOH}$ titration was carried out with a $\mathrm{NaOH} 0.02 \mathrm{~N}$ solution. Thanks to an optimization of the testing methods and of the experimental parameters, the absolute error associated with each measurement was in the order of $1 \mathrm{mmol}_{\mathrm{eq}} \mathrm{g}^{-1}$.

\section{Results and Discussion}

In order to reduce the clogging phenomenon during compounding and melt spinning, green monoconcentrated masterbatch was prepared using different processing parameters (Table III), and the clogging power of all industrial products was evaluated through Filter-Test analyses.

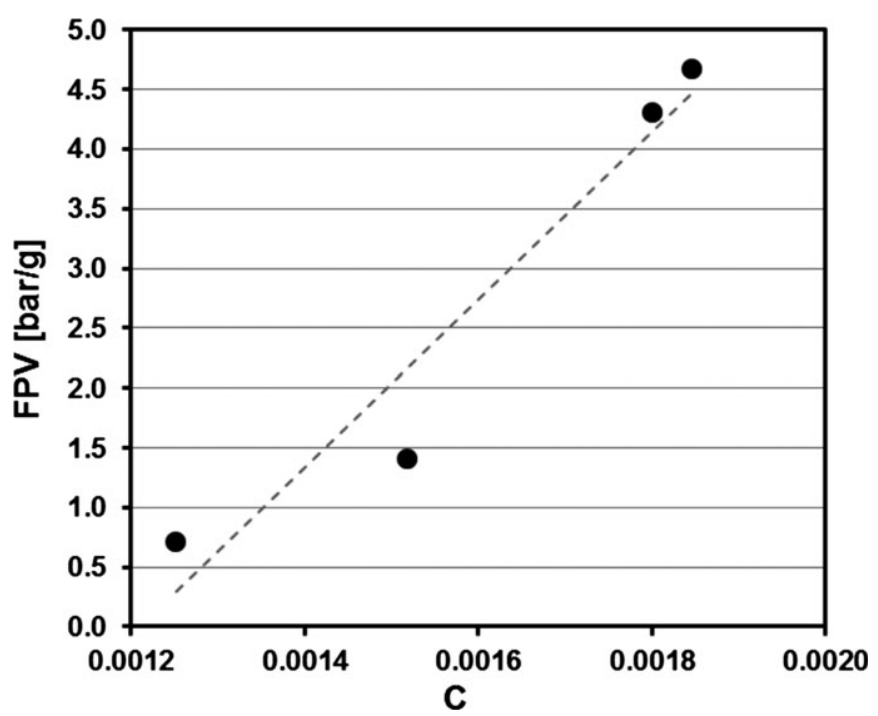

FIGURE 6. Correlation between FPV and C parameters of monoconcentrated green masterbatch.

The Filter-Test curves of the green masterbatch, reported in Fig. 3a, show three distinct regions. In the first region, the pressure remains constant due to the flow of neat (i.e., unfilled) PA6 matrix. After a rapid pressure increment, the second region is characterized by a near zero slope curve, that is related to the perfect balance between the pigment agglomerates that reach the filtration system and their disaggregation due to the polymer flow. The third region shows an important pressure drop. This is due to the bigger and unstable agglomerates that the green phthalocyanine pigment forms during the production. The mean values of FPV and FPVII for each processing condition are summarized in Fig. 3b. Taking into account standard deviation values, the FPV and FPVII values of filtered and unfiltered masterbatches are practically the same. Considering that masterbatch filterability seems to be unaffected by the filtration process, it can be concluded that filtration represents an unuseful processing step, that could be removed from the industrial layout of these products. Interestingly, second extrusion promotes an important reduction in the clogging power of the masterbatch, and this effect is even more evident upon a third extrusion. The 3E-W/O-F sample shows an FPV reduction of $84 \%$ with respect to the $1 \mathrm{E}-\mathrm{W}-\mathrm{F}$ compound. The variation between FPV and FPVII remains fairly constant for all the tested samples. This means that a change in the processing conditions reduces the aggregate size, without altering the filter clogging physical mechanism. However, it should be also taken into account that the thermomechanical re-processing of the monodispersed masterbatch could promote a partial thermo-oxidative degradation of the polymer matrix, affecting both the mechanical and the rheological properties of the PA6. Therefore, also this aspect should be considered in the analysis of FPV and FPV II values.

In Fig. 4 the results of color strength measurements, obtained by taking the color strength of the 1 E-W-F compound as reference, are summarized. This analysis confirmed the conclusions reported for Filter-Tests. The presence of the 
(a)

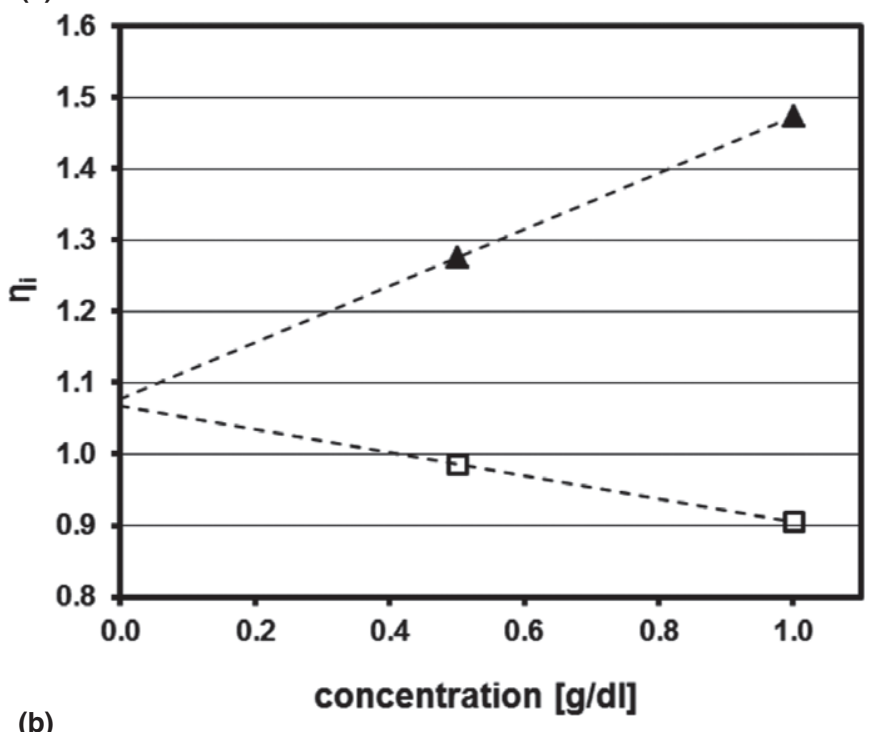

(b)



FIGURE 7. (a) Relative viscosity tests on 1 Extrusion W/O-F masterbatch. ( $\mathbf{\Delta})$ Reduced viscosity and $(\square)$ inherent viscosity. (b) Intrinsic viscosity values of masterbatch chips.

filter seems to slightly worsen the coloration capability of the matrix, with a limited decrease in RCS value. A second extrusion without filtration leads to a significant increase in RCS, and this effect is even more evident if a third extrusion is performed. In fact, 3 E-W/O-F sample shows a RCS value about $50 \%$ higher than the $1 \mathrm{E}-\mathrm{W}-\mathrm{F}$ green masterbatch. The observed increase in the coloration strength is probably related to an improvement of the pigment dispersion quality, achieved by applying a higher specific mechanical energy (SME) during the production process. Industrially speaking, a pronounced increase in the RCS value allows to reduce the pigment concentration in the compounds, thus increasing masterbatch stability and reducing the cost of the coloration process.

Rheological curves of the neat polymer matrix and of the monodispersed green masterbatches, obtained with one extrusion without filter, at two residence times in the rheometer $(3$ and $23 \mathrm{~min}$ ) are reported in Fig. 5a, while in Fig. $5 \mathrm{~b}$ zero shear viscosity values of the different masterbatches processed

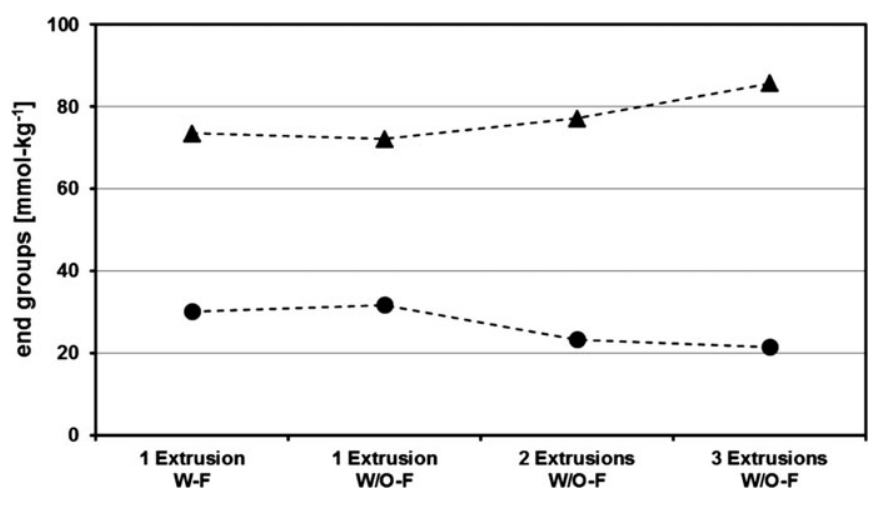

FIGURE 8. End group analysis on green masterbatches with different process conditions. $(\boldsymbol{O})$ aminic end groups and $(\boldsymbol{\Delta})$ carboxylic end groups.

at 3 and $23 \mathrm{~min}$ are summarized. Neat PA6, after $23 \mathrm{~min}$ at elevated temperature, exhibits a slight increase in apparent viscosity, because of post-condensation reaction that occurs inside the rheometer. ${ }^{27-29}$ During the thermal processing, amino and carboxylic end groups react with each other forming peptide groups and water, thus increasing the molecular weight of the polymer matrix and the apparent viscosity values. The presence of the green phthalocyanine pigment into the polyamide matrix markedly increases the apparent viscosity of the system in the whole shear rate interval. As often reported in literature, the molecular blocking effect promoted by the pigment aggregates into the polymer reduces the mobility of the molten polymer chains. ${ }^{30}$ After a residence time at of $23 \mathrm{~min}$ at $260^{\circ} \mathrm{C}$ an important reduction of viscosity was recorded for the compounded. This is probably due to the thermo-oxidative degradation of the matrix, promoted by the color pigment. For all the tested compositions, Cross model seems to satisfactorily fit experimental data over the whole range of shear rate, with an $R^{2}$ value higher than 0.995 for all the samples. The values of the zero shear rate viscosity of all the tested compositions, obtained through the interpolation of the rheological curves with the Cross model (Eq. 6), are summarized in Fig. 5b. The filtration process does not have any significant influence on the rheological behavior of the monodispersed green masterbatch while, increasing the specific mechanical energy supplied to the system with a second and a third extrusion, the zero shear rate viscosity was significantly reduced. As explained by Cassagnau, ${ }^{30}$ this melt viscosity reduction can be due to the improvement of the pigment dispersion quality, as detected in Filter Tests and in RCS analysis. However, also the contribution of the thermo-oxidative degradation, developed during the second and the third extrusions, could be taken into account. Figure 6 shows the correlation between FPV values, obtained from Filter-Tests, and the $\mathrm{C}$ parameter, determined through the fitting of rheological curves with the Cross model. A linear trend between these two parameters can be easily detected. Studies in the literature demonstrated the existence of relationship between the filterability of a filled polymer and its rheological properties. In particular, the higher values of the $C$ coefficient, proportional to the bonding energy between the particles under shear flow, the greater filler agglomeration and thus the 


\section{RESEARCH ARTICLE}

clogging effect of the filter. ${ }^{5}$ This probably means that the viscosity decrease experienced for repeated extrusions is influenced by the pigment disagglomeration.

Representative plots of reduced and inherent viscosity of 1 E-W/O-F monodispersed green masterbatch are reported in Fig. $7 \mathrm{a}$, while in Fig. $7 \mathrm{~b}$ the intrinsic viscosity values $\left(\eta_{i}\right)$ of all the tested samples, obtained from the convergence of reduced and inherent viscosity curves at zero concentration, are summarized. Intrinsic viscosity values of monoconcentrated green masterbatch is not practically affected by filtration system removal, and even in this case repeated extrusion stages leads to a noticeable decrease in the intrinsic viscosity values. Considering that intrinsic viscosity values of polymeric materials are not substantially affected by the presence of a non-interacting filler at limited concentrations, the observed trend can be related to the thermo-oxidative degradation that occurred inside the extruder during the third step, because of the prolonged thermo-mechanical processing. In order to confirm this hypothesis, in Fig. 8 the number of carboxylic and aminic functional groups of polyamide macromolecules, measured by end group analysis, are reported. As confirmed by previous tests, the concentration of both carboxylic and aminic terminations is not affected by the filtration stage. The second and the third extrusions determine an interesting increase in - $\mathrm{COOH}$ functionalities, accompanied by a reduction of $-\mathrm{NH}$ end groups. These variations are associated with a thermo-oxidation reaction of the polymer matrix ${ }^{31}$ occurred during prolonged thermo-mechanical process, that introduced oxygenated functionalities on the main backbone of the macromolecules decreasing the molecular weight of the matrix.

Concluding, thermomechanical re-processing of the monodispersed green masterbatch without filtration allows to improve the pigments dispersion within the polyamide but even promotes a thermo-oxidative degradation of the polymer matrix. Both these aspects affect the rheological behavior of the resulting materials and must be taken into account in an industrial compounding process.

\section{Conclusions}

A halogenated copper phthalocyanine color pigment was added to a commercial Polyamide 6 matrix to produce a monoconcentrated green masterbatch using different processing conditions. In particular, the effect of the extrusion number and the efficacy of the filtration operation were analyzed. Filter-Test analysis and color strength measurements demonstrated how the filtration system did not lead to an improvement in the dispersion quality of the master, and it could be eliminated from the industrial layout of the masterbatch production. On the contrary, repeated extrusions (i.e., enhanced $\mathrm{SME}$ involved in the production process) improved pigment dispersion, leading to a consistent reduction in the filter pressure value (FPV) and to an improvement of the relative color strength (RCS). Rheological tests and end group analysis demonstrated how a second and a third extrusion on the compounded materials determined a further filler disagglomeration and a partial thermo-oxidation of the polymer matrix. Concluding, the present work demonstrated how the optimization of the processing parameters of the masterbatch preparation allows to markedly improve both the processability and the coloration capability of the monoconcentrated green compounds.

\section{References}

1. Hao, Z.; Iqbal, A. Chem Soc Rev 1997, 26, 203-213.

2. Sargent, W. The Enjoyment and Use of Color; Dover Publications: New York, 1923.

3. Deshmukh, S. P.; Parmar, M. B.; Rao, A. C.; Wadhwa, V. Color Technol 2010, 126, 189-193.

4. Ahmed, S. I.; Shamey, R.; Christie, R. M.; Mather, R. R. Color Technol 2006, 122, 282-288.

5. Marcinčin, A. Prog Polym Sci 2002, 27, 853-913.

6. Buccella, M; Dorigato, A; Crugnola, F; Caldara, M; Fambri, L. J App Pol Sci 2015, 132, 41452

7. Lee Wo, D.; Tanner, R. Rheol Acta 2010, 49, 75-88.

8. Joshi, A.; Rathi, S.; Deshpande, S. Color Technol 2009, 125, 99-103.

9. Knor, N.; Walter, R.; Haupert, F. J Thermoplast Compos Mater 2011, 24, 185-205.

10. Godavarti, S.; Karwe, M. V. J Agric Eng Res 1997, 67, 277-287.

11. Liang, M.; Huff, H. E.; Hsieh, F. H. J Food Sci 2002, 67, 1803-1807.

12. Eise, K.; Herrmann, H.; Jakopin, S.; Burkhardt, U.; Werner, H. Adv Polym Technol 1981, 1, 18-39.

13. Ilo, S.; Tomschik, U.; Berghofer, E.; Mundigler, N. LWT - Food Sci Technol 1996, 29, 593-598.

14. Domenech, T.; Peuvrel-Disdier, E.; Vergnes, B. Compos Sci Technol 2013, 75, 7-14.

15. Gropper, M.; Moraru, C. L.; Kokini, J. L. Cereal Chem 2002, 79, 429-433.

16. Wildi, R. H.; Maier, C. Understanding Compounding; Hanser Publishers: Munich, Germany, 1998.

17. Herbst, W.; Hunger, K. Industrial Organic Pigments; Wiley: Weinheim, Germany, 2006.

18. Ludtge, C. Kunststoffe-Plast Europe 2005, 95, 176-177.

19. Klein, G. A. Industrial Color Physics; Springer: Berlin, Germany, 2010.

20. Zollinger, H. Color Chemistry: Syntheses, Properties, and Applications of Organic Dyes and Pigments; Wiley: Weinheim, Germany, 2003.

21. Ariño, I.; Kleist, U.; Rigdahl, M. Polym Eng Sci 2004, 44, 141-152.

22. Lewin, M. Handbook of Fiber Chemistry, 3rd ed.; Taylor \& Francis: Abingdon, UK, 2010.

23. Dijkstra, D. J. Pure Appl Chem 2009, 81, 339-349.

24. Cross, M. M. J Appl Polym Sci 1969, 13, 765-774.

25. Dealy, J. M.; Larson, R. G. Structure and Rheology of Molten Polymers: From Structure To Flow Behavior and Back Again; Carl Hanser Verlag: Munich, 2006.

26. Pamies, R.; Hernández Cifre, J.; del Carmen López Martínez, M.; de García la Torre, J. Colloid Polym Sci 2008, 286, 1223-1231.

27. Buccella, M.; Dorigato, A.; Caldara, M.; Pasqualini, E.; Fambri, L. J Polym Res 2013, 20, 225-233.

28. Buccella, M.; Dorigato, A.; Pasqualini, E.; Caldara, M.; Fambri, L. J Polym Res 2012, 19, 1-9.

29. Buccella, M.; Dorigato, A.; Pasqualini, E.; Caldara, M.; Fambri, L. Polymer Eng Sci 2014, 54, 158-165.

30. Cassagnau, P. Polymer 2008, 49, 2183-2196.

31. Ciaperoni, A.; Mula, A. Chimica e Tecnologia Delle Poliammidi; Pacini Editore: Pisa (Italy), 2001. 